\title{
What's gone wrong with the Contemporary Political Communication?
}

\author{
Alessandro Prato \\ Professor of Rhetoric and persuasive languages \\ Department of Political and Cognitive Social Sciences (DISPOC) \\ University of Siena, Siena \\ Italy
}

\begin{abstract}
The paper aims to investigate the mechanisms of incorrect and misleading reasoning with particular reference to the argumentative fallacies - ideas which many people believe to be true, but which is in fact false because it is based on incorrect information or reasoning - widely present today in information and communication policies, highlighting the strategies used to influence the behaviour of people and direct the formation of opinions in accordance with guidelines functional to systems of power.
\end{abstract}

Keywords: argumentation, manipulation, propaganda, fallacies, rhetoric

\section{Introduction}

The present article aims to illustratesome problematic aspects of contemporary political discourse and how public language is losing its power, and how an ominous gap is opening between the governed and those who govern.In particular we will examine and discussthese topics: 1. Information and political communication today often use the argumentative fallacies, that is a incorrect or misleading notion or opinion based on inaccurate facts or invalid reasoning, or an error in reasoning that renders an argument logically invalid;2. the strategies used to influence public opinion exploit the vast potential of emotional factors, which always play a central role in any kind of debate, instead the factor of rationality is less important.

The analysis is conducted using the tools of rhetoric, the branch of philosophy that Aristotle defined as "the faculty of observing in any given case the available means of persuasion" (Rhet. I, 2). It concerns the means which the orator can use to ensure that his speech will captivate the audience. Such means may be either rational or emotional ones.For our discussion we refer to the hermeneutical function of rhetoric (Reboul 1994: 22-25), it concerns the analysis and interpretation of arguments to assess the reliability of the proof confirming the theses they express.

\section{The personalization of political discourse}

In political discourse it is present more and more oftenthe ad hominem fallacy, or appeal to the person. This kind of fallacy occurs when one attempts to discredit a thesis by attacking some of the features of the person endorsing it (his/her physical appearance, habits, language, gender, culture, and so on), rather than by adducing relevant arguments against the thesis itself. In this kind of reasoning there is no logical relation between the premises and the conclusion, with the result that the latter is not inferred from the premises but arbitrarily postulated.

If, for example, Paolo puts forward various reasons in support of the use of the seatbelt, I would be behaving incorrectly if I were to dispute this idea by pointing out that Paolo has been charged with fraud. Paolo's arguments in favour of the seatbelt may be valid even if he is a man of questionable moral standing and ought to be examined independently of any opinion we may have about him, for in this case such an opinion is not relevant to the soundness of his thesis (Frixione 2009: 96). If a union representative argues that it is necessary to improve safety measures in the factory where he works, since these measures are inadequate to protect the workers, the safety manager may argue that this request cannot be taken into consideration because the union representative is not a credible interlocutor because in the 1960s he was jailed for resisting arrest. The manager's reasoning is incorrect because in this case he ought to evaluate the quality of the safety measures through a risk assessment process, and not judge the union representative's past experiences. While patently unfounded, the ad hominem fallacy often proves effective in electoral contexts, where it goes hand in hand with the phenomenon known as the "personalisation of politics", while also being well-suited to journalism. Oriana Fallaci (2011: 96), for example, resorted to this kind of fallacy in an interview with Arafat in the early 1970s. 
When Arafat argued that Arab rather than Greek culture ought to be credited with the invention of numbers and mathematics, the Italian journalist, who did not share this view, did not set out to show that Arafat's idea was wrong by providing evidence of the primacy of Western culture; instead, she sought to discredit Arafat himself by describing him in unflattering terms, relying on the fact that in the eyes of the public the negative picture she was painting of Arafat would also be seen to extend to his thesis.

It is not always easy to tell whether an ad hominem argument is being used in an acceptable way, not least because it is present in all forms of persuasion (Zagarella 2012: 134) and because the acknowledgement of the role played by the person in an argument - both on the interpersonal level and on the emotional one - is one of the cornerstones of rhetoric. From the very beginning, rhetoric has always regarded ethos, pathos and logos as the fundamental and necessary means of persuasion which an orator can employ in order to win over the audience, which will only trust $\mathrm{him} / \mathrm{her}$ if it can identify with his/her methods and approach (Leith 2011: 54-56). The very exponents of "New Rhetoric", Perelman and Tyteca (1958: 121), argue that there is such a close relation of interdependence between a person and his/her acts that we often tend to conflate these two very different levels.

As is widely known, Aristotle considered ethos an important benchmark for measuring the credibility of an orator within the framework - and by means - of his/her argumentation:

We trust in a greater degree and more readily persons of worth in regard to everything in general, but where there is no certainty and there is room for doubt, our confidence is absolute. But this confidence must be due to the speech itself, not to any preconceived idea of the speaker's character. We must not believe, as some writers argue in their techne, that the reliability of the orator in no way contributes to his powers of persuasion; on the contrary, character, so to say, constitutes the most effective pistis (Rhet, 1356a 4-13).

In other words, an orator's character is crucial insofar as it takes shape starting from his/her speech and harmonises with it: ethos is the product of logos, one of its functions. The ad hominem argument instead becomes an incorrect strategy of persuasion that only serves to manipulate the audience whenever it is not in harmony with the orator's argumentative strategy and indeed replaces it by simply discrediting one's interlocutor, thereby breaking that delicate balance between ethos and logos that Aristotle considered crucial.

One variant of the ad hominem fallacy is the tuquoque argument, which consists in claiming that a person's thesis is false because it stands in contradiction to his/her actions. For example: Lucy argues that all living beings have the right not to be harmed because they feel the same pain, and therefore that vivisection and animal testing are morally wrong; Jane, however, rejects this thesis because Lucy frequently buys products manufactured by pharmaceutical companies that engage in such practices. Jane's reaction is unacceptable because Lucy's inconsistent behaviour is not relevant for the sake of evaluating her thesis: her behaviour may be regarded as hypocritical, but her thesis is nonetheless sound.

In political discourse this strategy is used when in order to exonerate themselves from a charge of corruption, people argue that their opponents are guilty of the same crime; or when they argue that there is no point in showing indignation at the corruption of politicians since similar cases of corruption also occur among judges, policemen, doctors, and so on. In this case one speaks of a violation of relevance by symmetry. The aim is to suggest to the public the idea that if the blame is widespread, and if many people behave in a certain way, there is nothing to worry about and the problem ceases to exist. The outcome is paradoxical: if many people commit the same crime, unlawfulness is more widespread and the situation more serious; yet this is presented as a mitigating circumstance. Most of the time, this patent contradiction goes undetected by public opinion.

There is often a thin line between the tuquoque fallacy and a sound argument. The reason for this is that, generally speaking, there is an indisputable connection between a person and his/her acts, so that a person's merit is based on his/her behaviour. The constant relation between these two elements engenders what Perelman and Tyteca (1958: 315) have described as the "snowball effect". The mistakes made by a person and the role he/she plays with respect to the issue that is being debated can influence our assessment of his/her opinions. This is the case with conflicts of interest and testimonies, where the subject's behaviour is indeed relevant. In a debate on the hazards of smoking, a person downplaying the risks of smoking is hardly trustworthy if he/she is a tobacco manufacturer. It is clear that in this case the person's profile is relevant for the assessment of his/her opinions. Likewise, if a witness to a murder is shown to have been drunk at the time, this behaviour makes the testimony invalid (Frixione 2009: 35).

The ad verecundiam fallacy is based instead on the fear of challenging what one regards as an important and authoritative source. The expression means "pertaining to modesty", which leads the listener to rely on the opinion of what he/she regards as authoritative figures (Locke 1690: IV, 17, 19).A given thesis is considered valid not because of its intrinsic soundness, but because the person or institution upholding it is authoritative and enjoys a good reputation. Orators who resort to this fallacy do so in order to put pressure on the audience. 
They assert the consistency of their argument simply by invoking the statements made by an authoritative or influential person, such as the Pope or the President of the Republic. This is the case, for instance, when people claim that embryos are living beings, accepting the thesis endorsed by the Church simply because of the prestige and authoritativeness of this institution, and not on the basis of any critical analysis.

The elements introduced in the discussion are not pertinent, albeit in an opposite way compared to the ad hominem fallacy: instead of being employed to discredit one's opponent, these elements are used to argue that a given thesis is valid simply because it is acknowledged as such by an authoritative tradition or by established social convention. Not accepting the thesis, therefore, would be a sign of disrespect: once again, the attention shifts from rational proofs to elements that are extraneous to the discussion. In the aforementioned interview by Oriana Fallaci, the journalist also commits this kind of fallacy when she considers Western culture to be valid and superior in terms of its value system, deeming those who do not identify with it unworthy of social consideration. As in the case of the ad hominem fallacy, one of the fundamental laws of free debate is broken here (Emeren H.,GrootendorstR. 2004), namely respect for one's opponent and the admissibility of different points of view; when these no longer apply, debate becomes impossible and conversation turns into a monologue.

The lack of consideration and respect for one's opponent is rather common in public debate and also takes the form of the so-called scarecrow or straw man fallacy. The name comes from medieval jousting, when participants, before facing their opponents, would train using straw mannequins. The fallacy in this case lies in the fact that instead of refuting the thesis of one's opponent, the speaker refers to a different thesis (the "straw man") that is less plausible than the former and is specifically construed in such a way as to be more easily attacked. For example: in a television debate, A. argues that it would be important to ensure the rights of immigrants by avoiding indiscriminate repatriation and assessing each individual case; B. replies that it is unthinkable to welcome all asylum-seekers and accuses A. of seeking to destroy the country by accepting a ruinous invasion. B. response is misleading because A. has not said that we should accept all asylum requests indiscriminately. To take another example, A. argues that according to cognitive science the human brain works like a calculator; however, this is absurd because human memory does not work like the memory of a calculator; hence, cognitive science is wrong. The argument is false because cognitive science does not make this kind of claim at all: the speaker is painting a distorted and grotesque picture of the complex and multifaceted theses expounded by cognitive science.

\section{The incorrect and inappropriate arguments}

The issue of incorrect reasoning and fallacious argumentative techniques has been investigated throughout the history of rhetoric, from ancient Greece to the present day. It is examined both in Aristotle's Rhetoric and in the Sophistical Refutations, where it is noted that opinions presented in public speeches are based on arguments which, in turn, are based on inferential processes that enable one to draw a conclusion from some premises according to specific rules. Generally speaking, an argument is a reasoning (entimema) designed to provide reasons in support of a given claim; these reasons are the "premises", while the claim to be demonstrated is the "conclusion". The notion of entimemastands in contrast to that of apparent entimema which, just like the apparent syllogism, seems to be such but actually is not. According to Aristotle, the good orator must be familiar with misleading techniques of persuasion, so as to be able to avoid them in his own argument and expose them when they are used by his opponents.

An apparent entimema is one whose conclusion is not inferred from premises but simply juxtaposed to them; and this juxtaposition is precisely what misleads one's interlocutor, by giving him/her the impression of being presented with a syllogistic reasoning. This effect is created when an orator presents an unfounded causal relation - by stating for example that "since a man is elegant and roams about at night, he is an adulterer" (Rhet. 1401b 32) - or when he presents a temporal succession as though it were a causal relation: "Demades declared that the policy of Demosthenes was the cause of all evils, since it was followed by the war" (Rhet. 1401b 32). In these and other cases described by Aristotle, the fallacy lies in presenting a syllogistic chain which does not pass the falsifiability test, because the link between the various propositions de facto does not hold.

The issue of what causes produce a fallacious argument is also a central one for leading authors and texts in modern philosophy: from Petrus Ramus to Port Royal's Logique and later John Locke. The English philosopher discusses the issue of fallacies in several sections of his Essay on Human Understanding (1690) - both in the third book, devoted to words, and in the fourth, devoted to knowledge and probability. In particular, Locke identifies four kinds of fallacious argument to which people resort in order to win debates: argumentum ad verecundiam, argumentum ad ignorantiam, argumentum ad hominem, and argumentum ad judicem. These are typical examples of the kind of misleading argument which, as we will later see, refers to circumstances that are extraneous to the core of one's reasoning. Those who resort to these strategies do so in order to shift the public's attention away from the actual content of the argument by focusing it on extrinsic factors that are not relevant in themselves. 
Locke's classification of argumentative fallacies proved popular with later authors (Hamblin 1970: 210-25) and led to the identification of two other kinds of argument based on the same sort of logical error as the argumentum ad baculumand ad populum. We find these, for instance, in Jeremy Bentham's Book of Fallacies (1824) and in Richard Whately'sElements of Logic (1826).

In order to be plausible, an argument must meet two basic criteria: correctness and validity. According to the first criterion, the premises of a reasoning must be true; according to the second, the logical transition from the premises to the conclusion must be made correctly.

Fallacies - in particular so-called non-formal fallacies - are examples of an incorrect reasoning, and depend on many different factors: in some cases the premises are implausible because they are based on prejudices or stereotypes, if not on downright lies, or may be expressed in an ambiguous and confused way. In other cases, the premises are not germane to the argument and undermine the plausibility of the conclusion with respect to the possibility of obtaining new information.

While they are incorrect argumentative moves, fallacies may appear to be psychologically persuasive (Hamblin 1970). This is explained by the fact that unlike formal logic, within the framework of rhetoric argumentation deals with the practical applications of reasoning (e.g. in the ethical, political or legal field) and hence must also meet the additional criteria of efficacy and persuasiveness, which has significant psychological implications that are not easy to rationally control. This is why fallacies are so common: their apparent correctness makes them particularly suited to the intentional and deceptive manipulation of the audience for the purpose of producing a misleading persuasion. I will begin my enquiry by focusing on the "petitioprincipii", which in contemporary political communication has come to serve as the typical example of argumentative deception.

The petition principii is an incorrect argument because it includes the conclusion, which is to say what one wishes to prove, among the premises. This kind of argument was already criticised by Aristotle, who deemed it unacceptable. Nevertheless, it has continued to be widely employed in public speeches: for example, it is commonly found in the various forms of political communication because it has an apparently rigorous logical structure that will deceive an audience. Many messages that are addressed to the public implicitly - or even explicitly - include among their premises the conclusion, which is not the outcome of any reasoning but rather an axiom that is passed off as true without any proof.

For example, if in order to persuade an audience of the existence of God we say that "we know that God exists because we can see the perfect order of His Creation, an order which shows the supernatural intelligence of its Architect" we are slipping into this kind of fallacy because we are assuming that a creator and architect of the universe exists, and that the universe shows signs of an intelligent design, without providing any evidence in support of our thesis. This is a circular reasoning, then, because the premises and the conclusion can be inverted without changing the outcome.

Likewise, take the following claim: "Abortion is the unjustified killing of a human being; as such, it is murder. Murder is illegal. Hence, abortion should be illegal." This seems like a sound argument because if we assume that abortion is murder, it must follow that abortion ought to be illegal, since murder is illegal. But what seems like a rigorous and consistent reasoning is actually misleading because the last sentence merely reformulates a principle already expressed in the first premise - namely, the fact that the foetus may be regarded as a human being in every respect - without adducing any proof of this and indeed completely ignoring the ongoing controversy raging among jurists and scientists on the matter. The speaker simply assumes that abortion is murder, without providing any proof that might confirm this claim; hence, the conclusion that abortion also ought to be regarded as illegal is unfounded.

The petitioprincipii may vary widely in terms of content, while always maintaining the same argumentative structure. If we say that "children's memories of previous lives show that reincarnation exists, since the origin of those memories can only lie in past lives", we are once again committing an argumentative fallacy, since we are assuming that the children in question have lived past lives, which is to say that reincarnation is a real phenomenon. To argue that given memories find their origin in past lives is tantamount to claiming that past lives certainly exist, which is what ought to be demonstrated - not assumed.

The cases considered thus far are all examples of conceptual circularity. This kind of unfounded argument, however, can also take the form of procedural circularity (D'Agostini2012: 125), as in the case of fallacies of presupposition, where a premise is intentionally constructed by arbitrarily isolating an element from its context in such a way as to justify one's conclusion. When discussing the health risks of smoking in an address to Congress in 2009, Al Gore - the American Vice President under President Bill Clinton - criticised those doctors who still maintain that there is no proven link between smoking and lung cancer. 
After the speech, a commentator accused Gore of having argued that there is no proven correlation between smoking and lung cancer; Al Gore had indeed uttered that statement, only in a context in which he was making precisely the opposite claim.

The petition principii is also harmful because it distorts the very rules of debating: it requires the public to uncritically accept a thesis - as though it were a dogma - rather than to reason on a given problem so as to find the best solution. The moment we posit self-justifying principles, free discussion is over (Thompson 2016).

\section{When emotions are more important than reasoning}

In many circumstances, incorrect argumentative moves exploit the vast potential of emotional factors, which always play a central role in any kind of debate, to the point of allowing them to take over the whole argument and to override the factor of rationality. One fallacy of this sort is the ad misericordiam fallacy, which consists in making an appeal to the feeling of pity, by asking one's interlocutor to accept the conclusion of an argument not because of its soundness but merely on the basis of the emotions it stirs in him/her. One example is the case of the student who asks the examiner to give him/her a passing grade, or else he/she will lose his/her scholarship and be forced to quit university.

Eliciting strong feelings such as fear and indignation is a very effective means that orators have to capture voters' attention and win them over to their side. This is a technique widely used by totalitarian regimes - Fascism being a case in point - which typically combine the ad misericordiam argument with the captatiobenevolentiae in order to earn citizens' consensus, by showing that the people in power actually stem from their ranks. Consider the following extract from a speech which Mussolini delivered in Mantua on 25 October 1925:

Mine are not speeches in the traditional sense of the word: they are allocutions, points of contact between my soul and yours, between my heart and yours. My speeches, therefore, have nothing to do with the official, stiff speeches delivered in another age by men in lugubrious uniforms, men who could not address the people directly because the people did not understand them or love them (Mussolini 1983: 95).

These strategies are often associated with the ad populum argument, which exploits feelings shared by the audience and which are claimed to be well-founded merely by virtue of their popularity - as in the case of the commonplaces and stereotypes concerning immigrants, outcasts, homosexuals and anyone else who is viewed as being somehow different. The term demagogy is used precisely to describe an argumentative and political style that systematically resorts to this kind of argument (Pratkanis A., Aronson E. 1996).

In a debate, the rousing of passions is actually a useful means to influence and weaken one's opponent. For example, speakers might want to stir their opponents' anger by openly doing them wrong and behaving aggressively, because their angered opponents will then no longer be able to correctly assess what is most expedient for them. Indeed, resorting to the emotional aspect rather than reflection is one of the ten strategies identified by Chomsky (2004: 67) to create and control consensus. This technique is effective because it limits critical judgement in the listener and opens up the door to unconscious drives that allow the speaker to suggest ideas, desires or prejudices, to induce certain behaviour, or to make the listener unaware of errors, falsehoods and deceptions. The more emotionally aroused individuals are - gripped by anger, pain or elation - the less refined the categories through which they interpret the world around them (Billig 1991). An individual overwhelmed by emotions may operate an over-simplistic cognitive subdivision and reduce people to two categories alone: with or against me (Kertzer 1988).

With the ad baculum one instead seeks to make others accept a conclusion through a more or less explicit appeal to force. This strategy employs the weapon of blackmail, as in Mafia-style acts of intimidation, where shop-keepers are told that unless they pay they will be given no rest, as someone might burn down their stores; or as in those cases where workers are invited to accept unfavourable conditions because otherwise their contract may not be renewed. The subject here can no longer freely evaluate his/her interlocutor's suggestions and therefore the exchange is no longer dialectical.

As a means of persuasion, pathos is a test that must take place within the argumentation itself and not on the basis of external elements (Rhet. 1356a 14-15), in accordance with the kind of harmonious relation between reason and feelings that is totally lost in the cases we have been discussing, where it is replaced by an openly conflictual relation.

Each day, we receive messages of all sorts that ought to be carefully assessed in order to detect the different kinds of fallacies, identify the mechanisms of incorrect reasoning, and thereby protect ourselves from their persuasive potential. Democratic power still lies in the hands of citizens, who ought to assess the opinions of politicians and manipulators of public opinion (Chomsky 2004). The more aware people are of the importance of this power they wield and the better they learn how to use it, the weaker the poison infecting public debate will become, allowing our fragile and compromised democratic system to grow stronger and more solid. 


\section{References}

Aristotle(1959).ArsRhetorica, Oxford: Clarendon Press.

Aristotle (1995).SophisticiElenchi, Milano: Rizzoli.

Bentham, J. (1824).Handbook of Fallacies, London, Hunt.

Billig, M. (1991). Ideology and opinion. Studies in rhetorical psychology, London: Sage.

Cantù, P. (2011). E qui casca l'asino. Errori di ragionamento nel dibattito pubblico, Torino:Bollati Boringhieri,

Chomsky, N. (2004).Language and Politics, Chico:Ak Press.

D’Agostini, F. (2010).Verità avvelenata. Buoni e cattivi argomenti nel dibattito pubblico, Torino:Bollati Boringhieri.

Emeren, F.H., Grootendorst, R. (2004).A Systematic Theory of Argumentation. The Pragma-Dialectical Approach, London: Cambridge University.

Fallaci, O. (2011).Interview with History and Power, New York: Rizzoli International Publications.

Frixione, M.(2009).Come ragioniamo, Roma-Bari: Laterza.

Hamblin, C.K. (1970).Fallacies, London: Methuen.

Kertzer, D.I. (1988).Ritual Politics and Power, London:Yale University Press.

Leith, S. (2011).You Talkin' to Me?, London: Random.

Locke, J. (1690). Essay on Human Understanding, Oxford: Clarendon Press, 1975.

Meyer, M. (1993). Question de rhétorique. Langage, raison, séduction, Paris:LibrairieGénéraleFrançaise.

Perelman, C. andOlbrechtsTyteca, L. (1958).The New Rhetoric: Treatise on Argumentation, Notre Dame: University of Notre Dame Press, 1973.

Pratkanis A., Aronson E. (1996).Age of Propaganda: The Everyday Use and Abuse of Persuasion, New York: Macmillan.

Reboul, O. (1994).Introduction à la rhétorique, Paris: PUF.

Thompson, M. (2016).Enough said. What's gone wrong with the language of politics, New York: Macmillian.

Vickers, B. (1989).In Defence of Rhetoric, Oxford: Oxford University Press.

Zagarella, R.M.(2012). "Accordo e persona nell'argomentazione: il caso dell'adhominem". Rivista italiana di filosofia del linguaggio, 6, no. 3, pp. 133-47. 